\title{
KONTRIBUSI AGROFORESTRI TERHADAP KETAHANAN PANGAN RUMAH TANGGA PETANI DI DESA NGARIP KECAMATAN ULU BELU KABUPATEN TANGGAMUS
}

\author{
Susni Herwanti \\ Jurusan Kehutanan Fakultas Pertanian Universitas Lampung \\ Jl. Sumantri Brodjonegoro No.1 Bandar Lampung, Kode Pos 35145, Telp : (0721)701609 \\ Korespondensi Email : sh4nt@yahoo.com
}

Diterima : 10 Oktober $2016 \quad$ Disetujui : 11 November 2016

\begin{abstract}
Intisari
Agroforestri merupakan sistem penggunaan lahan yang mampu memberikan manfaat ekonomi, ekologi dan sosial termasuk di Desa Ngarip. Penelitian berupaya membuktikan kemampuan agroforestri secara ekonomi khususnya dalam menyediakan pangan bagi rumah tangga petani. Tujuan penelitian yaitu mengidentifikasi tanaman agroforestri, menganalisis ketersediaan pangan dari lahan agroforestri dan menentukan tingkat ketahanan pangan petani agroforestri. Sampel yang diambil berjumlah 93 responden, data primer dan data sekunder. Analisis data dilakukan secara deskriptif kualitatif. Hasil penelitian menunjukkan bahwa terdapat 40 jenis tanaman yang ada di lahan agroforestri yang terdiri dari sayur-sayuran, buah-buahan, umbi-umbian, biji-bijian, tanaman berkayu, rotan, bambu dan rumput. Berdasarkan analisis ketersediaan pangan, pangan yang tersedia dalam rumah tangga petani terdiri dari sayur-sayuran, buah-buahan dan biji-bijian. Penelitian menemukan bahwa rumah tangga petani Desa Ngarip memiliki tingkat ketahanan pangan yang cukup dengan skor sebesar 12,3.
\end{abstract}

Kata kunci: Agroforestri, Jenis Tanaman, Ketahanan Pangan, Ketersediaan Pangan.

\begin{abstract}
Agroforestry is a land use systems that are considered able to provide economic benefits, ecological and social, including in the village of Ngarip. This study seeks to prove the ability of agroforestry economy, especially in providing food for households. The purpose of this study is to identify agroforestry plants, analysis of food security of agroforestry and determine the level of food security of farmers agroforestry. Samples taken in this research is 93 respondents. Data collected in the form of primary data and secondary data. The data were analyzed descriptively qualitative. The results showed that there are 40 species of plants that exist in agroforestry, which consists of vegetables, fruits, tubers, grains, woody plants, rattan, bamboo and grass. Based on the analysis of food availability, food is available in the peasant households consisting of vegetables, fruits and grains. The study found that households Ngarip Village farmers have sufficient levels of food security with a score of 12.3 .
\end{abstract}

Keywords: Agroforestry, Food Availability, Food Security, Plant Species

\section{PENDAHULUAN}

Sistem agroforestri dianggap dapat memberikan manfaat secara ekonomi, ekologi dan sosial. Berbagai hasil penelitian menyebutkan bahwa agroforestri mampu meningkatkan perekonomian masyarakat sekitar hutan dan secara ekologi mampu memperbaiki kualitas lahan. Rauf et al. (2013) menyatakan bahwa salah satu keuntungan dalam penerapan sistem pertanian terpadu (termasuk 
sistem agroforestri) adalah peningkatan keluaran hasil (output) yang lebih bervariasi berupa pangan, pakan, serat, kayu, bahan bakar, pupuk hijau dan pupuk kandang. Hasil penelitian Mbow et al. (2014) menunjukkan bahwa agroforestri secara nyata berkontribusi terhadap ketahanan pangan, mitigasi dan adaptasi perubahan iklim pada bentang alam pedesaan Afrika. Selanjutnya agroforestri mampu menurunkan kerawanan pangan selama musim kering dan banjir di Kenya bagian Barat sebesar $25 \%$ karena pendapatan meningkat dan mata pencaharian penduduk membaik. Comia et al. (2015), praktek agroforestri memberikan kontribusi secara ekonomi dan ekologi dalam kehidupan bertani masyarakat yang hidup di sekitar Daerah Aliran Sungai (DAS) dengan memberikan jaminan ketahanan pangan di suatu wilayah.

Agroforestri yang diterapkan di lahan hutan kemasyarakatan (HKm) Desa Ngarip telah memberikan kontribusi sebesar $53 \%$ dari total pendapatan petani. Praktek agroforestri yang diterapkan di Desa Ngarip berupa kombinasi tanaman perkebunan dengan tanaman utama kopi, tanaman kehutanan, tanaman pertanian dan tanaman pakan ternak. Sistem agroforestri ini tentu menyediakan pangan bagi kebutuhan rumah tangga baik secara langsung maupun tidak langsung melalui hasil hutan bukan kayu (HHBK). Masyarakat Desa Ngarip secara langsung memanfaatkan tanaman agroforestri untuk kebutuhan pangan rumah tangga, namun kontribusi agroforestri terhadap ketahanan pangan rumah tangga petani belum diketahui secara. Pasti penelitian ini bertujuan untuk mengidentifikasi jenis tanaman agroforestri, menganalisis ketersediaan pangan dari lahan agroforestri dan menganalisis tingkat ketahanan pangan rumah tangga petani agroforestri.

\section{METODE PENELITIAN}

\section{Lokasi dan Waktu Penelitian}

Penelitian dilaksanakan di Desa Ngarip Kecamatan Ulu Belu Kabupaten Tanggamus Propinsi Lampung. Penelitian dilaksanakan pada bulan Agustus - September 2016.

\section{Metode Pengumpulan Data}

Data yang dikumpulkan berupa data primerdan data sekunder. Data primer dikumpulkan melalui observasi lapangan dan wawancara responden menggunakan kuesioner. Data primer terdiri dari data karakteristik sosial ekonomi, jenis tanaman agroforestri, harga jual per jenis tanaman dan frekuensi pemanenan. Data sekunder diperoleh melalui studi literatur, instansi setempat dan pustaka penunjang lainnya.

\section{Metode Penentuan Responden}

Penentuan responden dilakukan secara acak (random) terhadap total jumlah petani (1232 kepala keluarga) dengan menggunakan rumus Slovin.

$\mathrm{n}=\mathrm{N} /\left(1+\mathrm{Ne}^{\wedge} 2\right)$

keterangan:

$\mathrm{n}=$ Jumlah sampel

$\mathrm{N}=$ Total populasi

$\mathrm{e}=$ Toleransi nilai eror $(10 \%)$

Berdasarkan rumus Slovin, jumlah sampel yang diambil sebanyak 93 responden.

\section{Analisis Data}

Analisis data terbagi menjadi 3 bagian.

1. Analisis jenis tanaman agroforestri dilakukan secara deskriptif kualitatif

2. Analisis ketersediaan pangan dilakukan secara deskriptif dengan mengidentifikasi ketersediaan pangan dalam rumah tangga petani.

3. Analisis tingkat ketahanan pangan rumah tangga petani secara deskriptif. Ketahanan pangan diukur berdasarkan House hold food security acces scale (HFSAS) terhadap 9 item pernyataan dengan menggunakan 5 skala, yaitu tidak semua $=0$, jarang $=1$, kadangkadang $=2$, sering $=3$, sangat sering $=4$. Akses ketahanan pangan rumah tangga dihitung dengan menggunakan nilai Weight Mean Score (WMS). Penentuan level ketahanan pangan rumah tangga menggunakan skala yang sudah ditetapkan. Skala yang rendah menujunkkan tahan pangan, skala menengah menunjukan cukup pangan dan skala tinggi menunjukkan tidak tahan pangan. Nilai 
maksimum yang memungkinkan diperoleh adalah 24 dan nilai minimum adalah 0 . Penentuan ketahanan pangan menggunakan 3 kategori yaitu tahan pangan (0-9), cukup tahan pangan (10-18) dan tidak tahan pangan (19-27).

\section{HASIL DAN PEMBAHASAN}

\section{Karakteristik Responden}

Berdasarkan hasil analisis sosial ekonomi (Tabel 1), karakteristik responden menunjukkan bahwa semua responden bekerja sebagai petani lahan kering dengan mayoritas jenis kelamin adalah laki-laki (95\%). Responden di wilayah penelitian memiliki rentang umur dari 26 tahun - 80 tahun dengan persentase terbesar pada rentang umur 3039 tahun (34 \%) yang merupakan umur produktif. Menurut BPS (2014), umur produktif kerja 15-64 tahun. Hal ini berarti masyarakat di Desa Ngarip memiliki aktivitas bekerja yang cukup tinggi sebagai petani agroforestri. Hasil analisis status pernikahan, sebesar $95 \%$ responden menikah, $0,01 \%$ berstatus duda, $0,02 \%$ berstatus janda dan sebanyak $0,03 \%$ belum menikah. Berdasarkan tingkat pendidikan, sebesar $27 \%$ responden berpendidikan SMA, $32 \%$ tamat SMP, $28 \%$ lulus SD dan sisanya adalah pendidikan non formal dan tidak bersekolah. Hal ini menunjukan tingkat pendidikan masyarakat Desa Ngarip tergolong menengah karena mampu mengenyam pendidikan dasar 9 tahun. Masyarakat Desa Ngarip mayoritas (40\%) memiliki jumlah tanggungan sebanyak 3 orang. Hal ini berarti masyarakat memiliki tenaga kerja yang dapat membantu responden bekerja di lahan. Berdasarkan hasil penelitian, luas lahan petani berkisar antara $0,5-4$ ha dengan luas ratarata sebesar 1,5 hektar. Tingkat pendapatan petani dari lahan agroforestri mayoritas $(85 \%)$ lebih dari Rp10.000.000 tahun.
Tabel 1. Kondisi Sosial Ekonomi Responden

\begin{tabular}{lcc}
\hline Variabel Umur & Frekuensi & Persentase \% \\
\hline$\leq 30$ & 8 & 9 \\
\hline $30-39$ & 32 & 34 \\
\hline $40-49$ & 30 & 32 \\
\hline $50-59$ & 12 & 13 \\
\hline$>60$ & 11 & 12 \\
\hline Jenis kelamin & & \\
\hline Laki-laki & 88 & 95 \\
\hline Perempuan & 5 & 5 \\
\hline Status & & \\
\hline Menikah & 87 & 94 \\
\hline Janda & 2 & 2 \\
\hline Duda & 1 & 1 \\
\hline Belum menikah & 3 & 3 \\
\hline Ukuran rumah tang- & & 11 \\
\hline ga & 11 & 40 \\
\hline 3 & 39 & 29 \\
\hline 4 & 28 & 6 \\
\hline 5 & 6 & 9 \\
\hline$>5$ & 9 & \\
\hline
\end{tabular}

Tingkat pendidikan

\begin{tabular}{lcc}
\hline Tidak sekolah & 5 & 6 \\
\hline Tidak tamat SD & 4 & 4 \\
\hline SD & 26 & 28 \\
\hline SMP & 30 & 32 \\
\hline SMA & 25 & 27 \\
\hline Sekolah non formal & 3 & 3 \\
\hline
\end{tabular}

Luas lahan

\begin{tabular}{lll}
$\leq 1$ ha & 11 & 11 \\
\hline $1-2$ ha & 53 & 57 \\
\hline $2-3$ ha & 21 & 23 \\
\hline 3 ha & 8 & 9 \\
\hline
\end{tabular}

\begin{tabular}{lll}
\hline Pendapatan $(\mathrm{Rp} / \mathrm{th})$ & & \\
\hline 55.000 .000 & 8 & 9 \\
\hline 5.000 .000 & 7 & 8 \\
10.000 .000 & & \\
\hline$\geq 10.000 .000$ & 78 & 85 \\
\hline
\end{tabular}




\section{Identifikasi Jenis Tanaman Agroforestri}

Berdasarkan hasil penelitian, lahan agroforestri di Desa Ngarip memiliki 40 jenis tanaman yang terdiri dari sayur-sayuran, buah-buahan, biji-bijian, umbi-umbian, tanaman berkayu dan rumput Tabel 2 .

Tabel 2. Jenis Tanaman Di Lahan Agroforestri

\begin{tabular}{|c|c|c|}
\hline Nomor & $\begin{array}{l}\text { Jenis Tanaman } \\
\text { Agroforestri }\end{array}$ & Nama Latin \\
\hline \multicolumn{3}{|c|}{ Sayur-sayuran } \\
\hline 1 & Daun bawang & Allium Bstulosum \\
\hline 20 & Cabai & Capsicum frutescens \\
\hline 37 & Terong & Solanum melongenae \\
\hline $4 \mathrm{I}$ & Labu siam & Sechium edule \\
\hline 57 & Tomat & Lycopersicon esculentum \\
\hline $6 \mathrm{I}$ & Rampai & Solanumlycopersicumsyn \\
\hline $7 \quad 1$ & Kacang panjang & Vigna sinensis \\
\hline 81 & Petai & Parkia speciosa \\
\hline $9 \mathrm{~J}$ & Jengkol & Pithecelobium jiringa \\
\hline \multicolumn{3}{|c|}{ Buah-buahan } \\
\hline 10 & Jambu air & Psidium guajava \\
\hline 11 & Alpukat & Persea Americana \\
\hline 121 & Mangga & Mangifera indica \\
\hline 13 & Durian & Durio zibethinus \\
\hline 14 & Pisang & Musasp \\
\hline 15 & Nangka & Artocarpus heterophyllus \\
\hline 16 & Pepaya & Carica papaya \\
\hline 17 & Pinang & Areca catechu \\
\hline 18 & Melinio & Gnetum gnemon \\
\hline \multicolumn{3}{|c|}{ Umbi-umbian } \\
\hline 197 & Talas & Colocasia esculenta \\
\hline $20 s$ & Singkong & Manihot esculenta Crantz \\
\hline 21 & Kunyit & Curcuma domestica \\
\hline $22 \mathrm{I}$ & Laos & Languas galangal \\
\hline $23 \mathrm{~J}$ & Jahe & Zingiber offi cinale \\
\hline 24 & Kencur & Kaempferiagalangal \\
\hline \multicolumn{3}{|c|}{ Biji-bijian } \\
\hline 25 & Kopi & Coff ea robusta \\
\hline $26 \mathrm{I}$ & Lada & Piper nigrum \\
\hline $27 \quad 1$ & Kakao & $\square$ eobroma cacao \\
\hline 28 & Cengkeh & Eugenia aromatic \\
\hline 29 & Rumput gajah & Penisetum purpureum \\
\hline 30 & Aren & Arenga pinnata \\
\hline \multicolumn{3}{|c|}{ Tanaman berkayu } \\
\hline 31 & Mindi & M. azedarach \\
\hline $32 s$ & Sengon & P. falcataria \\
\hline 33 & Lamtoro & L. leucocephala \\
\hline
\end{tabular}

\begin{tabular}{lll}
\hline 34 & Cempaka & Micheliasp \\
\hline 35 & Gliriside & G. sepium \\
\hline 36 & Dadap & Erhytrina sp \\
\hline 37 & Kaliandra & C. calothyrsus \\
\hline 38 & Afrika & M.eminii \\
\hline 39 & Rotan & Calamus sp \\
\hline 40 & Bambu & Gigantochloa apus \\
\hline
\end{tabular}

\section{Ketersediaan Pangan Masyarakat Desa Ngarip}

Hasil penelitian menunjukkan bahwa ketersediaan pangandari lahan agroforestri bervariasi tergantung dari jenis tanaman. Semakin banyak jenis tanaman yang ada dan sudah berproduksi, semakin beragam jenis pangan yang tersedia. Jenis tanaman yang ada tidak semuanya menjadi pangan bagi petani karena beberapa jenis merupakan tanaman komersial yang hasilnya akan memberi keuntungan sehingga hanya jenis yang jumlahnya berlimpah atau tidak komersial saja yang menjadi pangan bagi petani. Jenis pangan agroforestri yang tersedia (100 $\%)$ adalah sayur-sayuran, buah-buahan dan kopi. Khusus buah-buahan, jenis buah yang tersedia bervariasi, namun secara umum semua responden mampu menyediakan buah-buahan dari lahan agroforestri. Jenis pangan lain adalah biji kopi. Semua responden mampu menyediakan biji kopi karena semua responden mengusahakan tanaman kopi sebagai komoditas utama di Desa Ngarip. Rekapitulasi ketersediaan pangan disajikan pada Tabel 3.

Tabel 3. Ketersediaan Pangan Dari Lahan Agroforestri

\begin{tabular}{clcc}
\hline \multirow{2}{*}{ Nomor } & Jenis Tanaman & \multicolumn{2}{c}{ Ketersediaan Pangan } \\
\cline { 3 - 4 } & Pangan Agroforestri & Tersedia & Tidak \\
\hline 1 & Sayur-sayuran & $100 \%$ & - \\
\hline 2 & Cabai & $94 \%$ & $6 \%$ \\
\hline 3 & Daun bawang & $32 \%$ & $68 \%$ \\
\hline 4 & Buah-buahan & $100 \%$ & - \\
\hline & -Jambu air & $31 \%$ & $69 \%$ \\
\hline & -pisang & $36 \%$ & $64 \%$ \\
\hline & -alpukat & $48 \%$ & $52 \%$ \\
\hline & -nangka & $32 \%$ & $68 \%$ \\
\hline 5 & Umbi-umbian & $64 \%$ & $36 \%$ \\
\hline 6 & Kopi & $100 \%$ & 0 \\
\hline 7 & Lada & $52 \%$ & $48 \%$ \\
\hline 8 & Jahe & $28 \%$ & $82 \%$ \\
\hline 9 & Madu & $0.01 \%$ & $99.09 \%$ \\
\hline
\end{tabular}




\section{Akses Ketahanan Pangan Rumah Tangga}

Tabel 3 menunjukkan bahwa masyarakat Desa Ngarip memiliki variasi makanan yang terbatas pada bulan-bulan tertentu. Hal ini ditunjukkan dengan skor nilai WMS sebesar 2,6 yang merupakan skor tertinggi (Rangking 1). Hasil penelitian Olaniyi (2013) menemukan bahwa masyarakat di Nigeria mempunyai pengalaman yang sama dengan nilai WMS tertinggi. Selain variasi makanan yang terbatas, masyarakat juga merasa kuatir anggota keluarganya tidak cukup makan. Hal ini ditunjukkan dengan skor WMS sebesar 2,4 yang berada pada urutan kedua. Masyarakat Desa Ngarip mengkonsumsi makanan yang tidak disukai pada saat-saat tertentu dan tidak mengkonsumsi jenis makanan yang disukai pada saat-saat tertentu yang ditunjukkan dengan nilai WMS yang sama sebesar 1,6 (Rangking 3). Dari semua item ketahanan pangan tersebut, pengalaman yang jarang dirasakan masyarakat adalah tidur kelaparan pada saat makanan tidak cukup. Hal ini ditunjukkan dengan nilai WMS yang paling rendah (Rangking 8). Menurut Olaniyi (2013), house hold food security acces scale dengan nilai tinggi berarti masyarakat tidak tahan pangan, sebaliknya nilai WMS yang rendah berarti masyarakat tahanpangan.
Selanjutnya berdasarkan hasil perhitungan ratarata skor ketahanan pangan, maka Desa Ngarip masuk dalam kategori cukup tahan pangan dengan skor 12,3. Penemuan (table 4) ini menunjukkan bahwa agroforestri mampu mencukupi kebutuhan pangan rumah tangga meskipun pangan yang disediakan dalam rumah tangga petani jenisnya terbatas.

\section{KESIMPULAN}

Jenis tanaman agroforestri petani terdapat 40 jenis yang terdiri dari sayur-sayuran, buah-buahan, umbi-umbian, rumput, rotan, bambu dan tanaman berkayu. Pangan agroforestri yang tersedia di rumah tangga petani terdiri dari sayur-sayuran, buah-buahan dan biji-bijian. Level ketahanan pangan rumah tangga agroforestri berada pada kategori cukup tahan pangan dengan skor sebesar 12,3 .

Tabel 4. Distribusi Responden Terhadap Akses Ketahanan Pangan Rumah Tangga

\begin{tabular}{lccccccc}
\hline Pengukuran & Sangat sering & Sering & $\begin{array}{c}\text { Kadang- } \\
\text { kadang }\end{array}$ & Jarang & $\begin{array}{c}\text { Bukan } \\
\text { semuanya }\end{array}$ & WMS & Ranking \\
\hline $\begin{array}{l}\text { Khawatir keluarga tidak cukup } \\
\text { makan }\end{array}$ & $11(12 \%)$ & $31(33 \%)$ & $33(35 \%)$ & $17(18 \%)$ & $1(2 \%)$ & 2,4 & 2 \\
\hline $\begin{array}{l}\text { Tidak dapat makan jenis makanan } \\
\text { yang disukai pada saat-saat tertentu }\end{array}$ & $1(1 \%)$ & $3(3 \%)$ & $48(52 \%)$ & $40(43 \%)$ & $1(2 \%)$ & 1,6 & 3 \\
\hline $\begin{array}{l}\text { Variasi makanan terbatas selama } \\
\text { bulan-bulan tertentu }\end{array}$ & $22(24 \%)$ & $31(33 \%)$ & $23(25 \%)$ & $17(18 \%)$ & $0(0 \%)$ & 2,6 & 1 \\
\hline $\begin{array}{l}\text { Makan makanan yang tidak disukai } \\
\text { pada saat-saat tertentu }\end{array}$ & $2(2 \%)$ & $0(0 \%)$ & $46(50 \%)$ & $45(48 \%)$ & $2(2 \%)$ & 1,6 & 3 \\
\hline $\begin{array}{l}\text { Makan makanan dengan porsi yang } \\
\text { lebih kecil dari biasanya karena } \\
\text { kurangnya sumber daya }\end{array}$ & $0(0 \%)$ & $5(5 \%)$ & $13(14 \%)$ & $52(56 \%)$ & $23(25 \%)$ & 1 & 4 \\
\hline $\begin{array}{l}\text { Makan makanan lebih sedikit dalam } \\
\text { sehari karena tidak ada cukup } \\
\text { makanan }\end{array}$ & $0(0 \%)$ & $0(0 \%)$ & $14(15 \%)$ & $41(44 \%)$ & $38(41 \%)$ & 0,74 & 5 \\
$\begin{array}{l}\text { Tidak makan apapun pada saat } \\
\text { tertentu }\end{array}$ & $0(0 \%)$ & $1(1 \%)$ & $21(24 \%)$ & $23(25 \%)$ & $47(50 \%)$ & 0,73 & 6 \\
\hline $\begin{array}{l}\text { Anggota keluarga tidur kelaparan } \\
\text { pada saat makanan tidak cukup }\end{array}$ & $0(0 \%)$ & $0(0 \%)$ & $4(4 \%)$ & $14(15 \%)$ & $75(80 \%)$ & 0,23 & 8 \\
\hline $\begin{array}{l}\text { Pergi seharian tanpa makan selama } \\
\text { makanan tidak cukup }\end{array}$ & $0(0 \%)$ & $0(0 \%)$ & $6(7 \%)$ & $20(21)$ & $67(72)$ & 0,34 & 7 \\
\hline
\end{tabular}




\section{DAFTAR PUSTAKA}

BPS. 2014. Laporan Bulanan Data SosialEkonomi. Badan Pusat Statistik Republik Indonesia. Jakarta.

Comia et al. 2015. Penilaian Jasa Ekologi dan Potensi Ketahanan Pangan dari Bentang Alam Agroforestri di Asia Tenggara: Kasus Makiling Forest Reserve di Filipina dan DAS Way Betung di Indonesia. Laporan Akhir. Kementerian Riset, Teknologi dan Pendidikan Tinggi Sekretariat Jenderal Seameo Seamolec Pusat Studi Regional Penelitian Biologi Tropis (Seameo Biotrop). Bogor.

Herwanti, S. 2012. Optimalisasi Pemanfaatan Lahan Hutan Kemasyarakatan Desa Ngarip Kecamatan Ulu Belu Kabupaten Tanggamus. [Tesis]. Sekolah Pascasarjana, Institut Pertanian Bogor. Bogor.
Mbow et al. 2014. Agroforestry Solutions to Address Food Security and Climate Change Challenges in Africa. Sciencedirect 2014 (6):61-67.

Rauf A. 2004. Kajian Sistem dan Optimasi Penggunaan Lahan Agroforestry di Kawasan Penyangga Tn Gunung Leuser: Studi Kasus di Kabupaten Langkat Sumatera Utara. [Tesis]. Sekolah Pascasarjana, Institut Pertanian Bogor. Bogor.

Olaniyi OA, Akintonde JO, Adetumbi SI. 2013. Contribution on Non Timber Forest Products to Household Food Security Among Rural Women in Iseyin Local Government Area of Oyo State, Nigeria. Research on Humanities and Social Sciences. 3(7): 41-49 